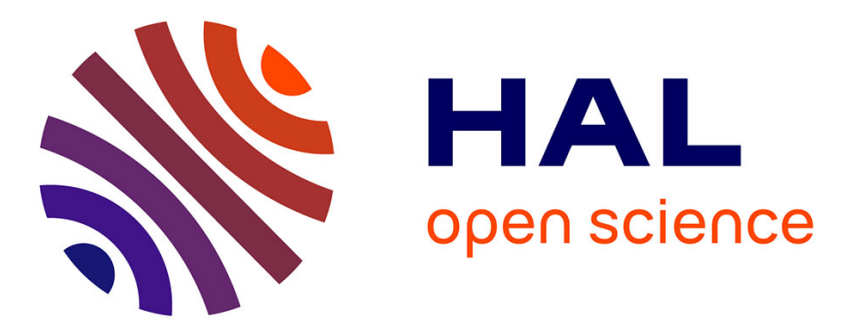

\title{
Digital Games in Primary Schools for the Development of Key Transversal Skills
}

\author{
Rosa Bottino, Augusto Chioccariello, Laura Freina, Mauro Tavella
}

\section{To cite this version:}

Rosa Bottino, Augusto Chioccariello, Laura Freina, Mauro Tavella. Digital Games in Primary Schools for the Development of Key Transversal Skills. 1st International Conference on Sustainable ICT, Education, and Learning (SUZA), Apr 2019, Zanzibar, Tanzania. pp.55-65, 10.1007/978-3-030-287641_8. hal-02515721

\author{
HAL Id: hal-02515721 \\ https://hal.inria.fr/hal-02515721
}

Submitted on 23 Mar 2020

HAL is a multi-disciplinary open access archive for the deposit and dissemination of scientific research documents, whether they are published or not. The documents may come from teaching and research institutions in France or abroad, or from public or private research centers.
L'archive ouverte pluridisciplinaire HAL, est destinée au dépôt et à la diffusion de documents scientifiques de niveau recherche, publiés ou non, émanant des établissements d'enseignement et de recherche français ou étrangers, des laboratoires publics ou privés. 


\title{
Digital Games in Primary Schools for the Development of Key Transversal Skills
}

\author{
Rosa Bottino, Augusto Chioccariello, Laura Freina and Mauro Tavella \\ Institute for Educational Technology of the Italian National Research Council, Via De Marini, \\ Genoa, Italy \\ bottino@itd.cnr.it
}

\begin{abstract}
Digital games are becoming more and more popular worldwide, arousing children's interest and fostering their motivation. Furthermore, tablets and smartphones are increasingly popular and widespread all around the globe, guaranteeing access to the web and to an ever-growing availability of games. This paper is based on the assumption that introducing digital game play into primary schools may support the development and consolidation of some transversal skills in a way that is perceived by students as interesting and motivating. When the games are carefully selected, the great effort spent by children in playing will provide them with the possibility to acquire and exercise, at an early age, basic skills which are important for their future. In particular, in this paper, different modalities in which digital games can be used in primary schools to foster basic transversal skills are presented. Logic and spatial reasoning skills as well as computational thinking are in particular considered. The reported experiments show that game based activities, when appropriately organized, can positively affect students' school performance as well as students' learning attitudes and behavior.
\end{abstract}

Keywords: Digital games, reasoning skills, visuospatial skills, computational thinking, primary school.

\section{Introduction}

It is generally accepted that in education a fundamental role is played by transversal skills such as logical reasoning, visuospatial abilities, computational thinking, etc. Therefore, fostering the development of these basic skills at a primary school level can enhance the students' performance, affecting positively their future results. However, these skills develop slowly and need a prolonged supporting action stretching over several years $[1,2]$.

Digital games are becoming more and more popular worldwide, arousing children's interest and fostering their motivation. Tablets and smartphones are widespread all around the globe, guaranteeing access to the web and to an evergrowing availability of games, a lot of which are free.

This paper is based on the assumption that introducing digital game play into primary schools may support the development and consolidation of some transversal 
skills in a way that is perceived by the students as interesting and motivating. When the games are carefully selected, the great effort spent by children in playing will provide them the possibility to acquire and exercise, at an early age, basic skills which are important for their future. Furthermore, if students' interest towards games is moved further and they are challenged to develop their own games rather than simply playing them, they can have the opportunity to develop computational thinking skills.

Many studies claim that computer games can positively affect learning and that their use can contribute to an effective educational innovation [3]. However, this assumption, taken as such, is too generic and there is the risk of falling into the old trap believing that the latest innovations are the best and should replace the previous learning approaches. The analysis of the efficacy for learning of the use of digital games is to be investigated in specific contexts and against clearly defined objectives and situations moving forward from the simple assumption that they are useful tools to engage and motivate students [4]. This paper reports studies in which the evaluation of the efficacy of games for learning is approached in a delimited context, while analyzing it in an articulated manner, making reference to the experience acquired in long-term studies and tackling the problem according to different perspectives which can complement each other.

In particular, different modalities in which digital games can be used in primary schools to foster basic transversal skills are presented. Logic and spatial reasoning skills as well as computational thinking are in particular considered. Specific reference is made to research projects performed at the Institute for Educational Technology of the Italian National Research Council. The experience gained in such studies supports the assumption that early and appropriately designed interventions focused on thinking skills carried out through game-based activities can positively affect students' school performance as well as students' learning attitudes and behavior $[5,6]$.

This paper, presents a methodology useful to foster, in primary school students, some basic transversal skills in a language independent manner. Skills such as logical reasoning and visuospatial abilities are at the basis of learning Science, Technology, Engineering, and Mathematics (STEM) [7] and are considered crucial for a fruitful integration into the $21^{\text {st }}$ Century digital world. The presented methodology and approach give several criteria for the selection of digital games, but do not rely on specific games. This guarantees that it can be adapted in time (as technology evolves and games change) and to different cultures and contexts.

Considering the specific context of developing countries and of Tanzania in particular, data from "We are Social - Hootsuite" [8] reports a great increase of the penetration of Internet in the last three years in Tanzania: in January 2019, 38\% of the population was reported to be users of the Internet, while in 2017 and 2018 the percentage was $14 \%$ and $15 \%$. Furthermore, $72 \%$ of the population has a mobile subscription, while the same percentage worldwide is lower (66\% to $68 \%$ in the three years). This shows that the availability of connectivity and tools to use digital games covers already a large percentage of the population, and such a percentage is increasing very fast. However, games that were used in the projects presented in this paper could all be downloaded and installed on tablets or computers, to be used also 
without a web connection. Moreover, all the chosen games were free. For these reasons, the proposed methodology and approach can be of interest for a variety of different contexts and situations, also considering their flexibility and adaptation opportunities.

\subsection{Playing and Making Games in Primary Education}

Different modalities can be adopted to integrate digital games in primary school education:

- use games explicitly implemented for educational purposes;

- select and use games that are not built for education to foster the development of specific and clearly identified abilities;

- introduce children to the construction of digital games through programming.

Since the main aim of the project which is considered in this paper is verifying under which conditions the use of games that are meant for entertainment may have a positive impact on education, the focus is kept on the latter two modalities.

A wide spectrum of game types is currently available off-the-shelf, including roleplays, adventures, brainteasers or mind games, serious games, etc. These also feature a range of different strategies such as free exploration/navigation, question and answer routines, artefact making, etc. In our work, we have addressed the use of games to foster basic cognitive abilities (i.e. logical reasoning and visuospatial skills) that have a correlation with school performance in STEM subjects. In particular, we considered the use of digital mind games (i.e. games like puzzles or brainteasers that require the enactment of thinking and reasoning skills). Even if it was suggested that they can be used in schools to foster learning [9], they are not frequently studied from the point of view of learning outcomes [10]. Our research studies highlighted their pedagogical potential to support and foster problem solving, reasoning skills and visual spatial abilities, showing that their use under certain conditions may also have a positive impact on school performance in curricular subjects such as mathematics.

Game making can be a very valuable educational activity, able to trigger students' transversal skills, such as reasoning abilities, creative attitudes and computational thinking skills [11]. Kafai and Burke [12] argued that student-designed games can teach not only programming but also academic subjects and transversal basic skills such as collaboration and teamwork. However, they do not suggest a shift to game making from game playing but rather argue for a more comprehensive, inclusive idea of game use in education in which both making and playing should be considered. Specific environments to support game making activities are available and there is an increasing interest in their educational use.

\section{The Project}

In a previous experience, the cognitive skills involved in the use of a selected number of mind games were studied [13] and a methodology, based on the use of mind 
games, to assess logical reasoning skills in children in the last two years of primary school was defined and thoroughly tested with more than 500 students in Italy [14].

Starting from this experience, the research group organized a project with the main objective of using digital games to foster some basic transversal skill in Italian primary school children. For this purpose, specific digital games were selected and a methodology for their use in compulsory education was defined and tested.

Table 1. The phases of the project

\begin{tabular}{|l|l|l|l|}
\hline Research questions & Focused Skills & Participants & Results \\
\hline $\begin{array}{l}\text { How to use digital } \\
\text { games in primary } \\
\text { classes to foster the } \\
\text { development of } \\
\text { logical thinking } \\
\text { abilities? }\end{array}$ & $\begin{array}{l}\text { Logical } \\
\text { thinking skills }\end{array}$ & $\begin{array}{l}\text { Four classes } \\
\text { (grades 4 to 7) } \\
77 \text { students from } \\
\text { Has their use an } \\
\text { impact on students' } \\
\text { math performance? }\end{array}$ & $\begin{array}{l}\text { A methodology (from skills } \\
\text { analysis to games selection and } \\
\text { their use in class) } \\
\text { Analysis of the impact on students } \\
\text { math performance (considering } \\
\text { the results obtained in a national } \\
\text { test) }\end{array}$ \\
\hline $\begin{array}{l}\text { Can games foster } \\
\text { visuospatial abilities } \\
\text { and have a positive } \\
\text { impact on school } \\
\text { results in } \\
\text { mathematics? }\end{array}$ & Visuospatial & $\begin{array}{l}\text { Reasoning } \\
\text { (grade 4 and 5) } \\
99 \text { students from } \\
9 \text { to } 11 .\end{array}$ & $\begin{array}{l}\text { Revised version of the } \\
\text { methodology. } \\
\text { Better results in the math posttest } \\
\text { for the experimental classes. }\end{array}$ \\
\hline $\begin{array}{l}\text { Would a learning } \\
\text { path focused on game } \\
\text { making in support of } \\
\text { computational } \\
\text { thinking work in } \\
\text { primary schools? }\end{array}$ & $\begin{array}{l}\text { Computational } \\
\text { Thinking }\end{array}$ & $\begin{array}{l}\text { One grade 5 class } \\
24 \text { students from } \\
10 \text { to } 11 .\end{array}$ & $\begin{array}{l}\text { A learning path for game making } \\
\text { with a visual programming tool. } \\
\text { Teacher guidelines for the use of } \\
\text { the learning path. }\end{array}$ \\
\hline
\end{tabular}

The project was organized in three different phases (see Table 1). In the first phase, logical thinking abilities were fostered through the use of selected digital games. In this phase, a methodology for the use of digital games in formal education was defined.

In the second phase, visuo-spatial abilities were considered. These include the ability to imagine an object and how it changes due to specific transformations (i.e. rotation, translation, changes in size, etc.) and being able to move in space and recognize a scene from different points of view. Selected off the shelf digital games were used, along with a virtual reality game that was specifically developed for the purpose. A preliminary study was carried out to assess the impact of the immersion in a virtual world on performance in a visuospatial task, in order to better guide the choice of the games. 
In the third phase, the activities moved to fostering computational thinking through game making activities in an online visual programming environment. In this paper, a preliminary case study is presented in which criteria for the introduction of coding in primary schools have been outlined.

\section{Use of Digital Games to Foster Logical Reasoning Abilities}

\subsection{Introduction}

In the first phase of the project we addressed the question on how to use digital games in primary classes to foster the development of logical thinking abilities.

The objective was to define a methodology addressing the analysis and selection of the games to be used as well as the organization and evaluation of the intervention involving primary school classes in close cooperation with the class teachers. Guidelines for game analysis and selection were developed as well as criteria to identify the specific skills to be fostered. This methodology can be adapted to different sets of abilities.

\subsection{Game Selection}

The chosen games were all freely available online, and were pre-selected according to the following criteria:

- they should entail some kind of logical reasoning (mind games);

- they were not linked to any specific arithmetic or language competence;

- the game play was not based on casual events, but rather strictly related to the player's moves;

- time, and therefore the speed of the player, did not influence results.

Some other characteristics of the games to be selected were also considered: the average duration of a play session, the availability of the game in different versions, languages, and levels of difficulty, the kind of immediate feedback provided by the game, its accessibility, as well as technical elements such as the needed technological support. Each selected mind game was then analysed with respect to the abilities needed to solve it. The following list reports the main abilities considered:

- knowing the rules of the game and being able to apply them in real game plays;

- making an inference based on the information available in a certain moment of the game and/or on constraints given by the game (one, two or more information/constraints);

- evaluating if the available information at a certain time in the game was sufficient to decide whether a move or a configuration was correct;

- being able to combine previous reasoning to complete a schema in the game. 


\subsection{Methodology and Results}

Guidelines for the organization of the training phase were then considered. This includes suggestions on the organization of the meetings and the needed tutoring support. Furthermore, guidelines on the duration of the whole intervention as well as each play session and their frequency were considered. Examples of supporting materials such as monitoring sheets, management of game feedbacks, final appreciation questionnaires for students, etc. are also provided.

The games were played in four different classes of the last years of an Italian primary school. Students played once a week with the selected games for a period of three months with the support of their class teacher and some researchers. All students showed a high interest in the game sessions. Qualitative data was collected both from direct observations and from final questionnaires and interviews with the students. Moreover, students' mathematics results from a national assessment test were analysed and the findings showed that experimental classes scored on average better than the other classes of the same school [5].

All students participated with great interest in the game activities and the impact of the experiment on the class climate was certainly positive.

The analysis of the collected data shows that strategies used by the students to solve the puzzles can improve significantly when the players receive a direct and personalized support when needed. The software characteristics that best support the addressed cognitive processes were analysed and specific recommendations have been added to the methodology. However, personalized support can be difficult to obtain when the number of teachers is limited with respect to the number of students. For this reason, the adaptation of existing games with the aim of making them more suited to actually support the development of the basic skills addressed, in particular with respect to the game feedbacks, was also considered. An open source version of the classic Master Mind game was modified to include both the possibility to trace the players moves and to give them personalized feedback based on the game play [15].

\section{$4 \quad$ Use of Digital Games to Foster Visuo-Spatial Skills}

\subsection{Introduction}

In the second phase of the project, the methodology developed in the first phase was applied to an intervention aimed at fostering visuospatial abilities in students of the last two years of primary school (aged 9-11) [16]. The methodology was thus tested and refined in order to guarantee that it could be applied to different sets of abilities.

Visuospatial abilities include several different skills and there is no unique definition in literature. Nevertheless, all authors agree in including two main elements: the ability to imagine a two or three dimensional object in space and understand how it changes when moved, rotated, reflected or stretched, and the ability to understand positions in space, to recognize the relative position of a set of objects, and to understand what it would look like from a different points of view. 
Several studies demonstrated that there is a close correlation between visuospatial abilities and achievements in STEM related subjects [7]. Other studies showed that these abilities can be improved with a specific training and such an improvement is transferred to different contexts and lasts in time [17]. Consequently, a game-based training of visuospatial abilities in primary students was organized and its impact on school results in mathematics was measured.

\subsection{The Preliminary Study}

As the addressed skills were analyzed, the strong embodied characteristics of visuospatial abilities emerged. A preliminary study was thus organized to assess the impact of immersion in a virtual world on the enactment of these abilities.

The digital game "In Your Eyes" was developed to be used for this preliminary study. The game is focused on Visual Perspective Taking: the ability to understand how a given scene would look like from the point of view of another person. The game takes place in a virtual living room, with a table in the middle and some objects on it. Four screens on the wall show the pictures of the table taken from the four sides. A virtual non player character moves to one side of the table, and then asks the player to select the picture showing the table as he sees it. The player can move in the room but has to go to a defined play position to answer.

The game is available in three different versions: a complete immersive version (which uses a Head Mounted Display), a semi-immersive version where the virtual world is seen through the computer screen, and a non-immersive one in which the player has only a fixed view of the room and cannot move.

"In Your Eyes" was tested with a limited number of students to measure the impact on performance of the different levels of immersion. Results show that the nonimmersive version obtained the worst results, while the other two obtained very similar results, and differences were not statistically significant [18].

Due to these results, along with restrictions due to the limited availability of the Head Mounted Displays and some motion sickness experienced by some students it was decided not to use immersive games in the subsequent phase of the project. Thus, all the games chosen were either on tablets or standard computers.

\subsection{Methodology and Results}

Applying the previously defined methodology, the visuospatial abilities to be addressed were then detailed. The main abilities considered were: visual memory, visuo-motor coordination, the ability to imagine a bi- or three dimensional shape, the ability to understand what three dimensional object results from folding a two dimensional shape, finding strategies for filling an area or a volume, and orienting oneself in space.

Based on these abilities, a wide set of games was analysed and selected. At each meeting, one of the previously mentioned abilities was addressed, and several games were offered to the students, allowing them to choose freely according to their interests and abilities. A complete set of monitoring tools was defined, including 
observation sheets, questionnaires and interviews. A standardized math test was chosen to measure the students' mathematical achievements across different classes [19]. The test was given before the start of the training sessions and at the end of the project.

Data analysis showed that those classes that followed the game session performed statistically better at the standardized math post-test when compared to control classes that followed the traditional curriculum [16].

All the involved students were enthusiastic of the game activities and participated with great commitment, even though with large differences both with respect to the kinds of games they chose and the level of difficulty they could reach.

During the study, it was noticed that students are deeply involved in playing and participated with interest to all the different activities. Nevertheless, the involvement and interest measured were higher in those games that required a more active participation from the children. For instance, they particularly like Minecraft [20], a sandbox game that allows them to play with digital building blocks. Starting from this observation, it was decided to widen the proposed experiences to include not only game playing but also game creation and development. Actually, it is possible to play by the rules, following a given game as it was conceived by its creator, or with the rules, finding inspiration from known games to build a new, personalized one.

\section{$5 \quad$ Boost Computational Thinking through Game Making Activities}

\section{$5.1 \quad$ Introduction}

In the third phase, a game making activity is introduced. The main objective was to foster the development of Computational Thinking (CT) abilities in students of the last year of primary school in a visual, block-based programming environment. Scratch [21], a visual programming environment where the instructions are assembled like LEGO building blocks, was chosen. Scratch is specifically designed for children from 8 up, it is free and available online, which allows students to continue their work outside school hours.

CT, as defined by Wing [22], is "the thought processes involved in formulating problems and their solutions so that the solutions are represented in a form that can effectively be carried out by an information-processing agent”. It entails logical reasoning to solve problems and understand artefacts, procedures and systems. It includes a set of skills that are also at the basis of STEM subjects.

In order to define a methodology for the introduction of game making in primary schools, a single exploratory case study was organized, with students from the last years of an Italian primary school [23]. Among the main objectives of this phase was the definition of a learning path to be used in the following years directly by teachers. 


\subsection{Methodology and Results}

The learning path was completely developed before the start of the school year, including a first part devoted to introducing students to the programming environment and to some basic concepts underlying the coding activity, followed by a role play in which students, organized into small groups, played the role of game developers.

In order to be ready to support students in the best possible way, a complete scaffolding was devised, to be used according to the class needs. This included a set of instructions that could be more or less detailed according to the needs, specific lessons with the class as a whole to solve together technical issues, some concrete activities to be used as a starting point to understand deeply a certain procedure, etc.

The learning path was then tested in a grade 5 class of an Italian primary school as a single explorative case study, involving all the students and their class teacher, for a period of about seven months. Some trainee teachers were also involved, mainly to carry out the observations. Teachers, trainee teachers, and researchers played the role of tutors to help the groups with their work. At the end of the project, each group managed to have a working prototype of their game, which was then presented to the families and the head of the school.

Students, in average, had no previous coding experience and few opportunities to code outside school hours; nevertheless, they all managed to play an active role in the creation of their own game. Results show that most students were very interested in the coding activities and gained an increasing amount of independence. Guidelines for teachers willing to organize a similar experience were then defined, with reference to the Italian context [23].

The case study, even though successful, evidenced some issues of concern that have to be closely considered when organizing similar interventions.

Since in the Italian primary schools there is no specialist information technology teacher, class teachers have to play an active role. However, teachers often had difficulty in managing learning paths involving programming activities.

Furthermore, the abilities that are at the basis of CT develop slowly. The case study showed that students would have needed a much longer time to really master the activities and their teachers were not yet adequately prepared to support their growth. For this reason, a longitudinal three-year long experiment has been planned, starting in the school year 2018-2019, involving the introduction of computational thinking skills by means of game-making and interactive story telling activities with pupils from the third to the fifth primary school grade.

\section{Conclusions and Future Work}

A project spanning over several years was organized to investigate the use of noneducational digital games to foster the development of some transversal abilities that are at the basis of the study of STEM related subjects. The project aimed at the definition of a methodology for the use of games in primary classes that can then be reused and adapted to different skills and contexts. 
With respect to the use of off-the-shelf games, the methodology was defined and tested in the Italian context. It is sufficiently general to be adapted to different games and abilities. Some elements will need a deeper study. For example, results show that students improve better their play strategies when they receive personalized support. This could be achieved through an adaptation of the games to be used, enriching them with specific feedback functionalities.

In the third phase of the project, a game making approach was experimented, and gave good results. Nevertheless, a much longer time period, spanning over all the primary grades, would allow students to gain the needed experience and increase their coding abilities. At present, a long term study is being carried out including grades 3 to 5 of a primary school. Data is being collected with respect to every student showing their gradual improvement in coding and will be analyzed at the end of every school year.

\section{References}

1. King, P. M., \& Kitchener, K. S.: Developing Reflective Judgment: Understanding and Promoting Intellectual Growth and Critical Thinking in Adolescents and Adults. JosseyBass Higher and Adult Education Series and Jossey-Bass Social and Behavioral Science Series. Jossey-Bass, 350 Sansome Street, San Francisco, CA 94104-1310 (1994).

2. Edwards, S.: Digital play in the early years: a contextual response to the problem of integrating technologies and play-based pedagogies in the early childhood curriculum. European early childhood education research journal, 21(2), 199-212 (2013).

3. De Freitas, S., \& Liarokapis, F.: Serious games: a new paradigm for education?. In Serious games and edutainment applications (pp. 9-23). Springer, London (2011).

4. Whitton, N.: Learning with digital games: A practical guide to engaging students in higher education. Routledge (2009).

5. Bottino, R. M., Ferlino, L., Ott, M., \& Tavella, M.: Developing strategic and reasoning abilities with computer games at primary school level. Computers \& Education, 49(4), pp. 1272-1286 (2007).

6. Bottino, R. M., Ott, M., \& Tavella, M.: Children’s performance with digital mind games and evidence for learning behaviour. In World Summit on Knowledge Society (pp. 235243). Springer, Berlin, Heidelberg (2011). DOI: 10.1007/978-3-642-35879-1_28

7. Newcombe, N. S.: Picture This: Increasing Math and Science Learning by Improving Spatial Thinking. American Educator, 34(2), 29 (2010).

8. We are Social - Hootsuite, https://datareportal.com/reports, last accessed 2019/03/05.

9. Vaegs, T., Dugosija, D., Hackenbracht, S., \& Hannemann, A.: Learning by gaming: facts and myths. International Journal of Technology Enhanced Learning, 2(1-2), pp. 21-40 (2010).

10. Facer, K., Ulicsak, M., \& Sandford, R.: Can computer games go to school? Emerging technologies for learning, 2(5) (2007).

11. Bottino, R., \& Chioccariello, A.: Computational Thinking: videogames, educational robotics, and other powerful ideas to think with. KEYCIT: Key Competencies in Informatics and ICT, 7, 301 (2015).

12. Kafai, Y. B., \& Burke, Q.: Connected gaming: What making video games can teach us about learning and literacy. Mit Press (2016). 
13. Bottino, R.M., Ott, M.: Mind games, reasoning skills, and the primary school curriculum: hints from a field experiment, Learning Media \& Technology, Taylor and Francis, 31(4), pp. 359-375 (2006).

14. Bottino, R. M., Ott, M., \& Tavella, M.: Serious gaming at school: Reflections on students' performance, engagement and motivation. International Journal of Game-Based Learning (IJGBL), 4(1), 21-36 (2014). DOI: 10.4018/IJGBL.2014010102.

15. Bottino, R. M., Ott, M., \& Benigno, V.: Digital mind games: experience-based reflections on design and interface features supporting the development of reasoning skills. In Proc. 3rd European Conference on Game Based Learning, pp. 53-61 (2009).

16. Freina, L., Bottino, R., Ferlino, L., Tavella, M.: Training of Spatial Abilities with Digital Games: Impact on Mathematics Performance of Primary School Students. Proceedings of the Game and Learning Alliance International Conference (GALA) (December 5-7, 2017, Lisbon, Portugal) (2017).

17. Uttal, D. H., Meadow, N. G., Tipton, E., Hand, L. L., Alden, A. R., Warren, C., \& Newcombe, N. S.: The malleability of spatial skills: a meta-analysis of training studies. Psychological bulletin, 139(2), 352 (2013).

18. Freina, L., Bottino, R., Tavella, M., \& Dagnino, F.: Immersion's impact on performance in a spatial reasoning task. In International Conference on Games and Learning Alliance (pp. 211-220). Springer, Cham (2016).

19. Cornoldi, C., Cornoldi, C., Lucangeli, D., Bellina, M.: AC-MT 6-11. Test di valutazione delle abilità di calcolo e soluzione dei problemi. Gruppo MT. Con CD-ROM. Edizioni Erickson (2012).

20. https://www.minecraft.net/ - last accessed 2019/03/14

21. Resnick, M., Maloney, J., Monroy-Hernández, A., Rusk, N., Eastmond, E., Brennan, K., ... \& Kafai, Y.: Scratch: programming for all. Communications of the ACM, 52(11), 60-67 (2009).

22. Wing, J.: Research Notebook: Computational Thinking - What and Why? The Link. Pittsburgh, PA: Carneige Mellon. (2011).

23. Freina, L., Bottino, R., \& Ferlino, L.: A Learning Path in Support of Computational Thinking in the Last Years of Primary School. In Proceedings of the Game and Learning Alliance International Conference (GALA), December 5-7, 2018, Palermo, Italy (2018). 